\title{
Manufacturing an upset end by friction welding in an API X65 steel
}

\author{
Guilherme Vieira Braga Lemos ${ }^{1 *}$ (1) \\ Diogo Buzzatti ${ }^{\prime}$ \\ Carla Amavisca ${ }^{1}$ \\ Giovani Dalpiaz ${ }^{2}$ \\ Marcelo Torres Piza Paes ${ }^{2}$ \\ Luis Kanan \\ Afonso Reguly ${ }^{\prime}$
}

\begin{abstract}
Deepwater and ultra-deepwater oil and gas exploitation might be challenge due to the fatigue damage at the touchdown zone (TDZ). Therefore, the development of risers with thicker pipe ends (upset end) is a solution to diminish issues related to fatigue through reducing the average axial stress. In the current study, manufacturing of an upset end was carried out by friction welding in an API X65 PLS2 steel pipe with outer diameter of $220 \mathrm{~mm}$. Considering the welding geometry called 'tube to tube', pipe sections were machined with different thickness. Thus, in the welding process, the rotational speed was employed in the upset (thicker pipe), while the axial force was applied in the thinner pipe. Hence, this work presents the feasibility of manufacturing an upset end through friction welding and the metallurgical and mechanical properties of the joint. The results showed a suitable welded joint with good top surface appearance and no defects. The samples have not fractured in fatigue tests, which indicate high fatigue life.
\end{abstract}

Keywords: Manufacturing; Friction welding; API X65; Upset end; Fatigue properties.

\section{Introduction}

Steel catenary risers (SCR) are an economical solution in deep and ultra-deep water exploration systems, where a high degree of reliability is required [1,2]. Within this framework, the API 5L X65 PSL2, a high-strength low-alloy steel (HSLA) with minimum yield strength of $450 \mathrm{MPa}$, good weldability and corrosion properties has been widely used [3]. However, several factors can contribute to the deterioration of fatigue properties in locations close to the joint region at the touchdown zone (TDZ), such as the riser dimensions (size), mechanical loading caused by the environment, production fluid, exploration depth, among others [4,5]. Figure 1 shows a schematic drawn of the upset end at the TDZ.

The concept of pipes with thicker wall at the pipe end (known as upset end) was reported by the Joint Industry Project (JIP) [7,8]. The aim was to increase the fatigue properties of SCR and, especially, in the region of contact with TDZ. Case studies considered techniques such as pipe machining, deposition by welding and local forging of the pipe end (upset end) for application of sections with thick ends to improve the fatigue performance over a normal pipe joint, which enhancement may be achieved by reducing stress concentration factor [7,9]. The multiple solutions available are interesting to provide a comparative assessment between them, thus allowing the selection of the most technicaleconomic suitable for a given request $[4,8]$. Finally, it is remarkable to note that there has not been found a friction welding application to manufacture an upset end.

Among the technologies with potential for producing an upset end, friction welding is a great alternative that can bring several advantages, since issues related to solidification, porosity, hydrogen embrittlement, corrosion, distortion, and high levels of residual stress can be avoided or limited to some extent [10-14]. In short, friction welding uses the heat thermomechanically generated to plasticize alloys in the solid state mode and further produce sound joints [15-18]. The present study aims to develop an alternative route to manufacture an upset end (increasing in the pipe wall thickness) by friction welding. This methodology was applied to an API 5L X65 PSL2 steel. Furthermore, mechanical and metallurgical features of the joint were investigated.

\section{Materials and methods}

Base material (BM) pipe was evaluated to confirm its properties and features. BM characterization was undertaken

\footnotetext{
${ }^{1}$ Laboratório de Metalurgia Física - LAMEF, Programa de Pós-graduação em Engenharia de Minas, Metalúrgica e de Materiais - PPGE3M, Universidade Federal do Rio Grande do Sul - UFRGS, Porto Alegre, RS, Brasil.

${ }^{2}$ Centro de Pesquisa da Petrobras - CENPES, Petróleo Brasileiro S. A., Rio de Janeiro, RJ, Brasil.

*Corresponding author: guilherme.lemos@ufrgs.br
} 
by chemical composition (optical emission spectrometer) and tensile tests. Therefore, considering a sample thickness close to that of the pipe wall, three specimens were machined. The sample dimensions are shown in Figure 2.

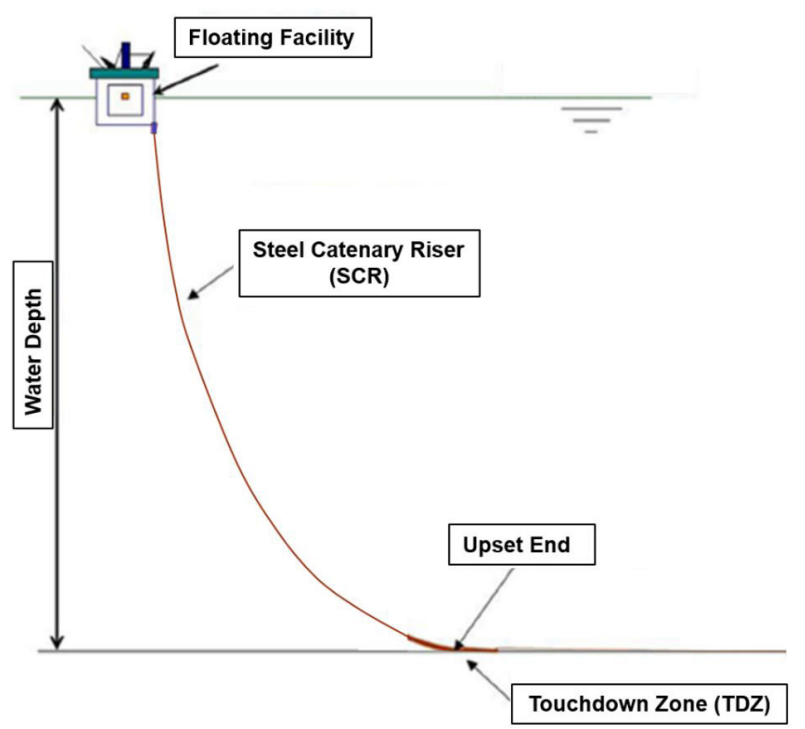

Figure 1. Schematic drawn of a SCR with upset end at the TDZ. Adapted from Mekha et al. [6].
To produce the upset end, the pipes were machined with the same inner diameter and varied pipe walls. This allowed having distinct pipe thickness and a thicker upset. In Figure 3, the steps of the upset production can be observed. In this sense, Figure 3 a shows both pipes without contact, while Figure $3 b$ presents the axial force applied to the thinner pipe (yellow arrow) and the rotation of the thicker pipe (red arrow) to produce the upset end through friction welding, and Figure $3 c$ the pipes in another perspective. Hence, this welding geometry was named as "tube to tube".

Conventional metallography procedures were adopted and the samples were etched by Nital 5\%. Macro and microstructural features were observed by optical microscopy $(\mathrm{OM})$. Furthermore, microhardness measurements were carried out in the BM and the welded joint.

Mechanical properties were investigated via tensile tests at room temperature (RT) according to the ASTM E8/E8M standard [19]. Thus, four samples were tested. The specimen's location is shown in Figure 4a and their dimensions in Figure 4b. It should be noted that these properties were evaluated with subsize specimens due to the limitations with regard to the size of the joint.

Based on the suggested real application of the upset end (see Figure 1), it was essential to evaluate fatigue properties. Therefore, nine samples were submitted to fatigue

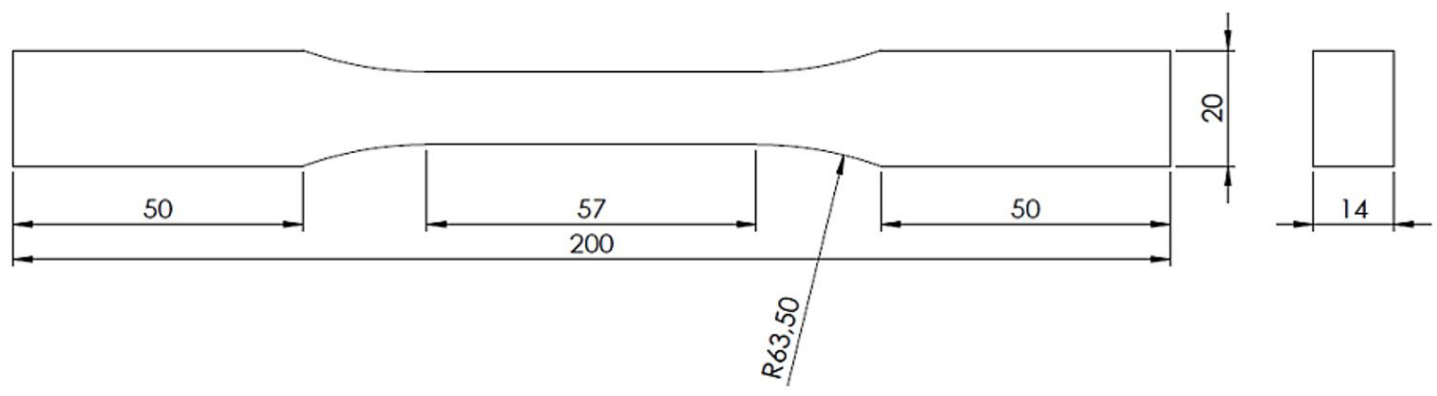

Figure 2. Tensile testing specimen (dimensions in $\mathrm{mm}$ ).
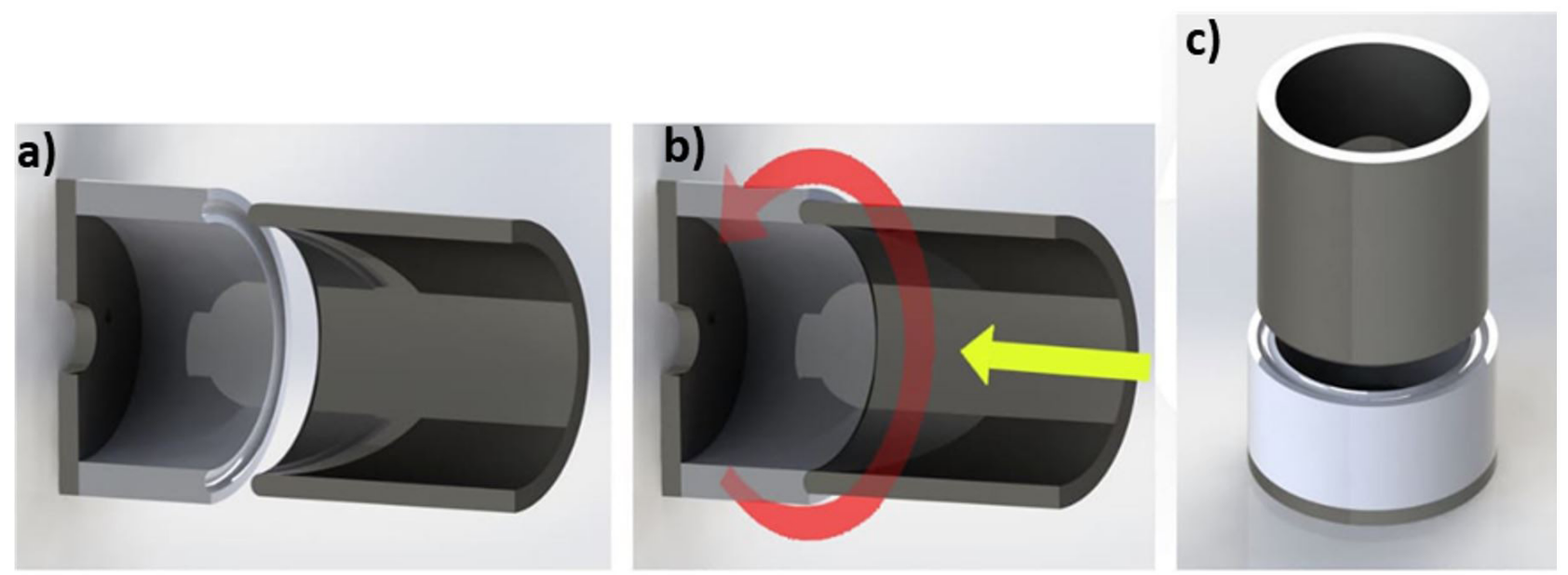

Figure 3. Schematic draw showing the steps for an upset production: (a) pipes without contact; (b) friction welding process; and (c) geometry "tube to tube". 
tests at RT, with parameters shown in Table 1. Finally, Figure 5a presents the samples location in the welded pipe and Figure $5 \mathrm{~b}$ their dimensions.

\section{Results and discussion}

The BM pipe has the following chemical composition: $0.098 \%$ C, $1.41 \% \mathrm{Mn}, 0.009 \% \mathrm{P}, 0.003 \% \mathrm{~S}, 0.264 \% \mathrm{Si}$,
$0.07 \% \mathrm{Cr}, 0.051 \% \mathrm{Mo}, 0.015 \% \mathrm{Ni}$, and $0.026 \% \mathrm{~V}$. These data were compared to the API 5L standard [3] and proved to be in compliance. The carbon equivalent (CE) according to the Equation 1 (Ito \& Bessyo's Pcm equation) was 0.189 and also showed to be within the required limits $(\mathrm{CE}=0.25$ max. for PSL2 grade).

$$
C E=C+\frac{S i}{30}+\frac{M n}{20}+\frac{C u}{20}+\frac{N i}{60}+\frac{C r}{20}+\frac{M o}{15}+\frac{V}{10}+5 B
$$

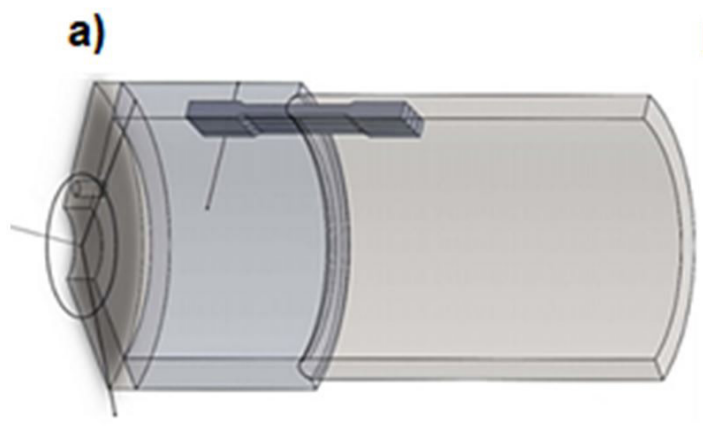

b)
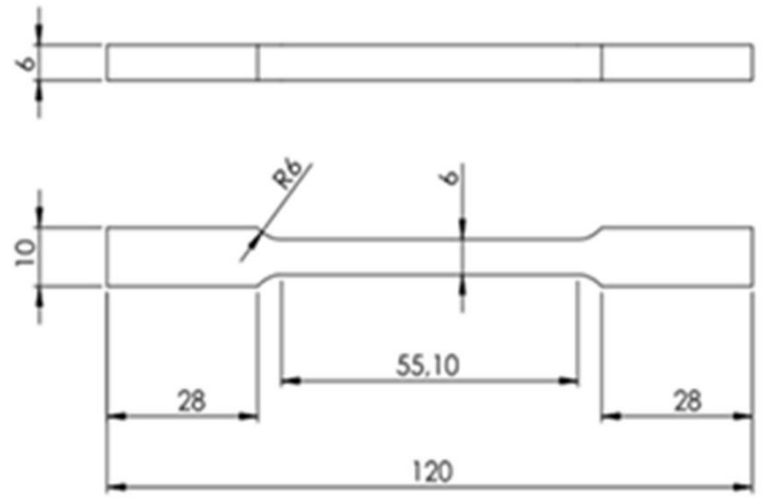

Figure 4. Tensile test specimens: (a) location; (b) sample dimensions [in mm].

Table 1. Fatigue test parameters

\begin{tabular}{cccccccccc}
\hline Sample & $\begin{array}{c}\text { Range } \boldsymbol{\sigma} \\
(\mathbf{M P a})\end{array}$ & $\begin{array}{c}\boldsymbol{\sigma} \mathbf{m a x} \\
(\mathbf{M P a})\end{array}$ & $\begin{array}{c}\boldsymbol{\sigma} \text { min } \\
(\mathbf{M P a})\end{array}$ & $\begin{array}{c}\boldsymbol{\sigma} \text { average } \\
(\mathbf{M P a})\end{array}$ & Area $\left(\mathbf{m m}^{2}\right)$ & $\begin{array}{c}\text { Load max } \\
(\mathbf{k N})\end{array}$ & $\begin{array}{c}\text { Load min } \\
(\mathbf{k N})\end{array}$ & $\begin{array}{c}\text { Ratio } \\
(\mathbf{c y c l e s})\end{array}$ \\
\hline 1 & 220 & 250 & 30 & 140 & 20.85 & 5.212 & 0.625 & 0.12 & $10^{6}$ \\
2 & & 250 & 30 & 140 & 20.85 & 5.212 & 0.625 & 0.12 & $10^{6}$ \\
3 & & 250 & 30 & 140 & 20.85 & 5.212 & 0.625 & 0.12 & $10^{6}$ \\
4 & 200 & 220 & 20 & 120 & 20.85 & 4.587 & 0.417 & 0.091 & $10^{6}$ \\
5 & & 220 & 20 & 120 & 20.85 & 4.587 & 0.417 & 0.091 \\
6 & & 220 & 20 & 120 & 20.85 & 4.587 & 0.417 & 0.091 & $10^{6}$ \\
7 & \multirow{2}{*}{180} & 200 & 20 & 110 & 20.85 & 4.17 & 0.417 & 0.1 & $3 \times 10^{6}$ \\
8 & & 200 & 20 & 110 & 20.85 & 4.17 & 0.417 & 0.1 & $3 \times 10^{6}$ \\
9 & & 200 & 20 & 110 & 20.85 & 4.17 & 0.417 & 0.1 & $3 \times 10^{6}$ \\
\hline
\end{tabular}

a)

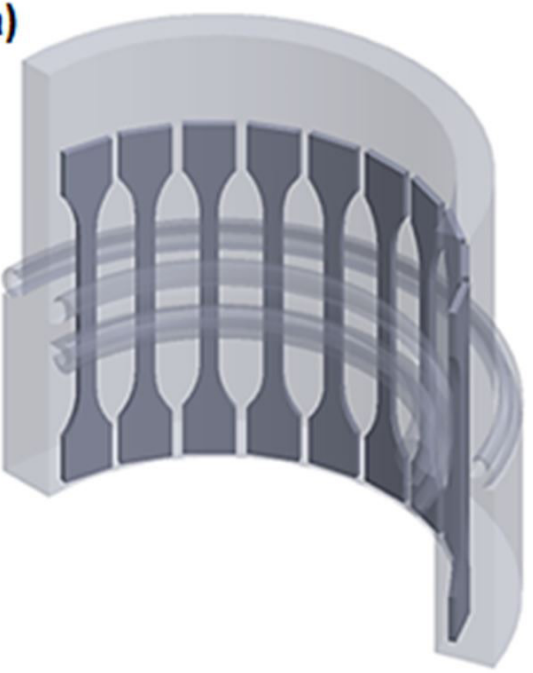

b)

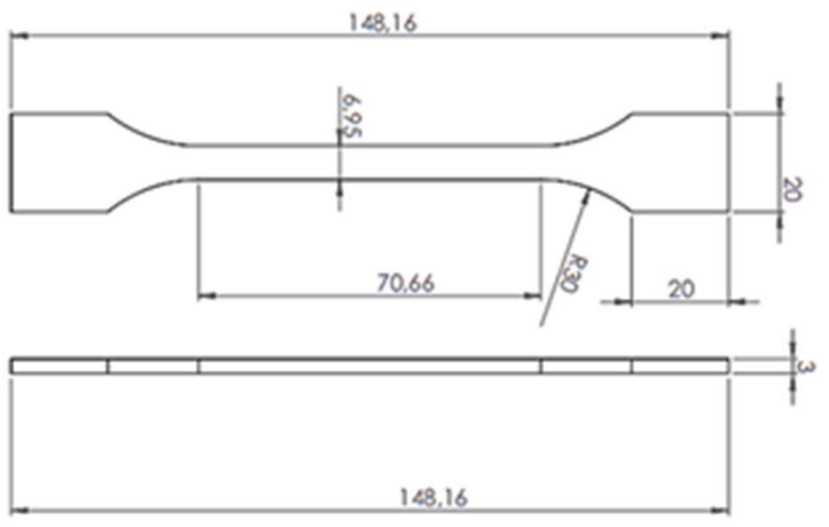

Figure 5. Fatigue test specimens: (a) position; (b) sample dimensions [in mm]. 
As an average, microhardness in the longitudinal direction was $178 \mathrm{HV}$, while in the cross section it was 175 HV. Therefore, microhardness measurements met the specifications of API 5L standard and requirements for materials used in deep water (hardness lower than 250 HV10) $[3,20]$.

Considering tensile test specimens with the maximum available thickness (according to the machine's capacity), the test results were found to be adequate. Thus, the mean yield strength (YS) and ultimate tensile strength (UTS) values, 463 and $548 \mathrm{MPa}$, respectively, were within the specifications for API X65 PSL2. Therefore, based on these analyzes (chemical composition and tensile tests), it can be concluded that the BM is an API 5L X65 PSL2 steel.

\subsection{Friction welding}

The top surface appearance of the welded joint is shown in Figure 6. As can be seen, this joint showed no defects or discontinuities. To the complementary analyses, flash and excess of material have been removed.

Figure 7 shows the macrograph of the joint. In general, a good joint can be observed, without the presence of defects and unsuitable bonding. Moreover, a white layer can be noted in the center of the weld. Some specific regions of this joint (indicated by the letters in the macrostructure) were analyzed with respect to their microstructures, as further shown in Figure 8.

In Figure 8, selected regions of the macrostructure (Figure 7) present different microstructural features. The Figure 8a shows the upset HAZ microstructure that is based on polygonal ferrite $(\mathrm{PF})$ with grain growth, fine pearlite $(\mathrm{P})$ and acicular ferrite (AF). In the upset TMAZ (Figure 8b), the main microstructure is $\mathrm{AF}$ and $\mathrm{PF}$, although $\mathrm{P}$ can be noted. Next, in Figure 8c, there is a complex microstructure composed by $\mathrm{P}$ (or aggregates of carbides) between the ferrite grains and probably the M/A constituent. A clear weld interface, $\mathrm{PF}$, and grains relatively coarsened (in comparison to the regions a) and b)) were also seen. In the pipe TMAZ (Figure 8d), AF, PF, and P can be observed. The pipe HAZ region (Figure 8e) also revealed AF, PF, and P. Finally, in Figure $8 \mathrm{f}$, the $\mathrm{BM}$ microstructure is shown, which is based on small-sized ferrite.

The microhardness profile is shown in Figure 9. As can be noted, the microhardness values in the joint did not exceed the recommendations of API 5L standard. In the TMAZ region, a microhardness enhancement was noted, which is typical in friction welding [21,22]. This improvement might be related to harder microstructures or even carbides promoted by friction welding. Moreover, the diminished microhardness values found in HAZ region may be related to the PF amount and its coarsened grains.

Figure 10 presents the average mechanical properties of the BM pipe and welded joint obtained by subsize specimens. For the welded pipe, the mean YS and UTS was $344 \mathrm{MPa}$ and $504 \mathrm{MPa}$, respectively. Still, both (base material and welded joint) have similar UTS. Moreover, a slightly reduction in YS was noted in the joint. An optimization of the process parameters can be further developed to enhance the joint mechanical properties.

Table 2 shows the fatigue test results. The samples $(1,2,3$ and 4$)$, even tested with the highest loads and runout of $10^{6}$ cycles have not fractured, which indicate high fatigue life. Still, none of the specimens has broken. Therefore, the welded joint achieved suitable fatigue properties.

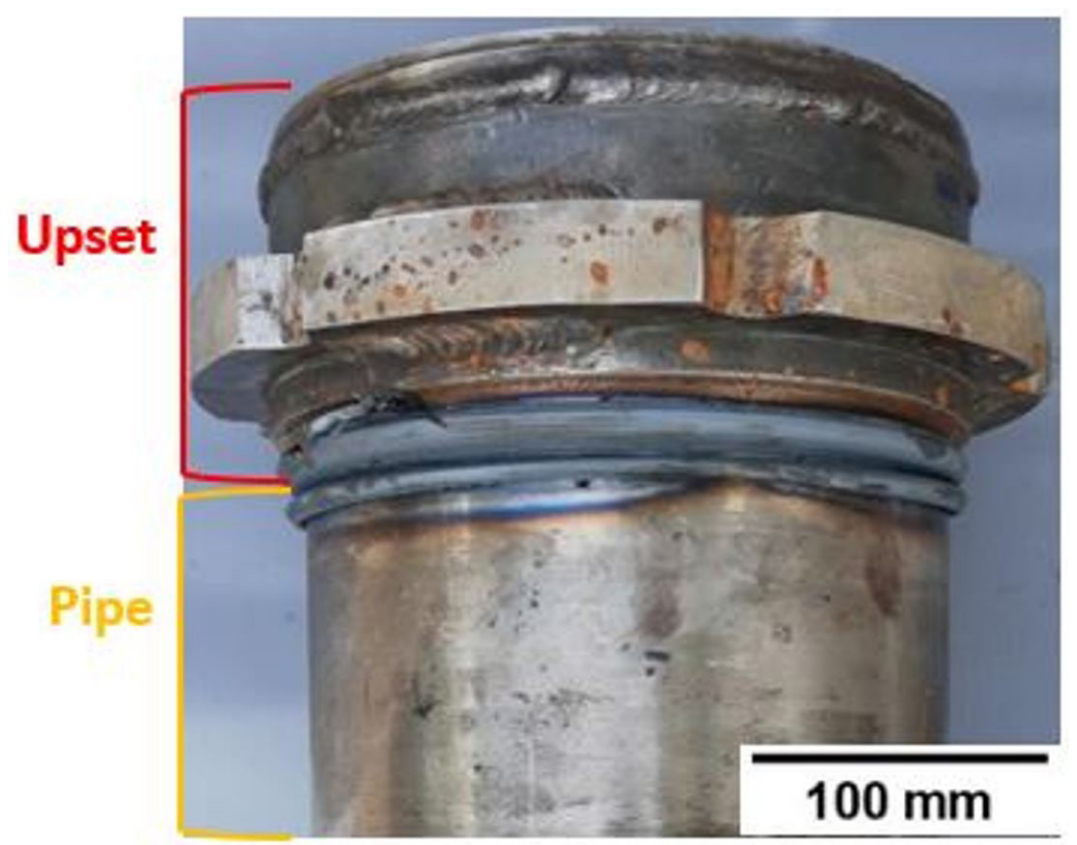

Figure 6. Top surface appearance of the welded joint. 


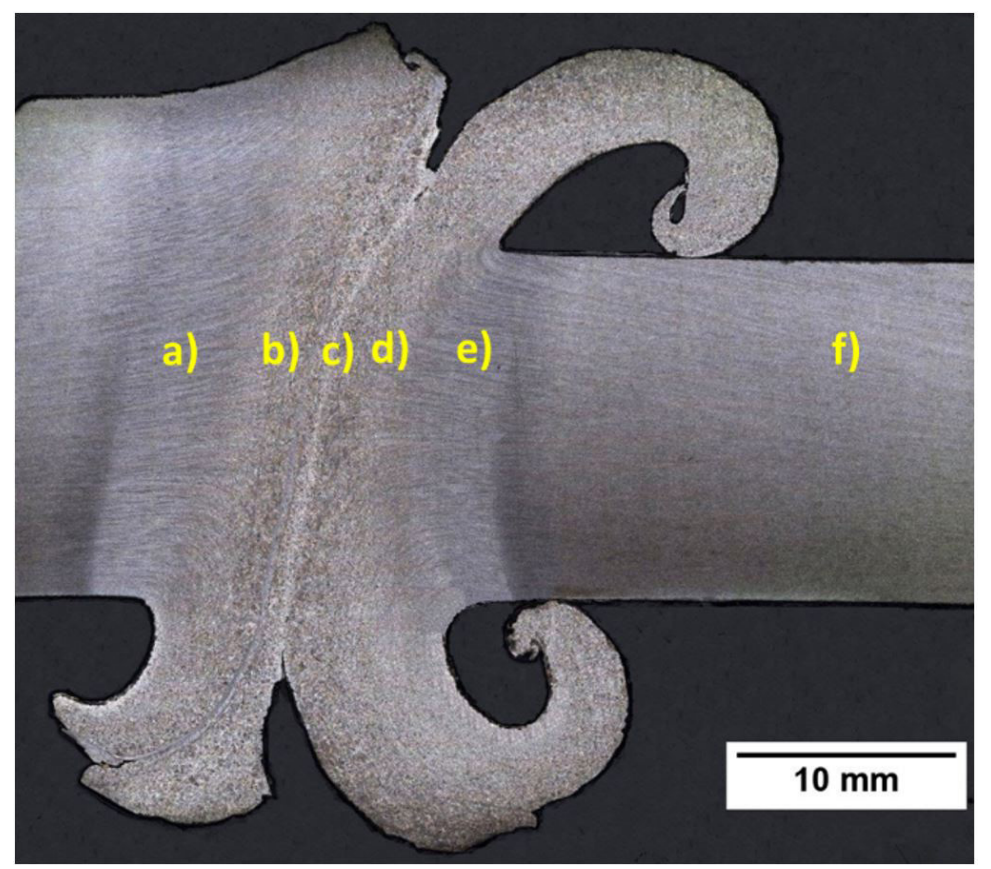

Figure 7. Macrostructure of the welded joint. Etching by Nital 5\%. a), b), c), d), e), and f) are detailed in Figure 8.
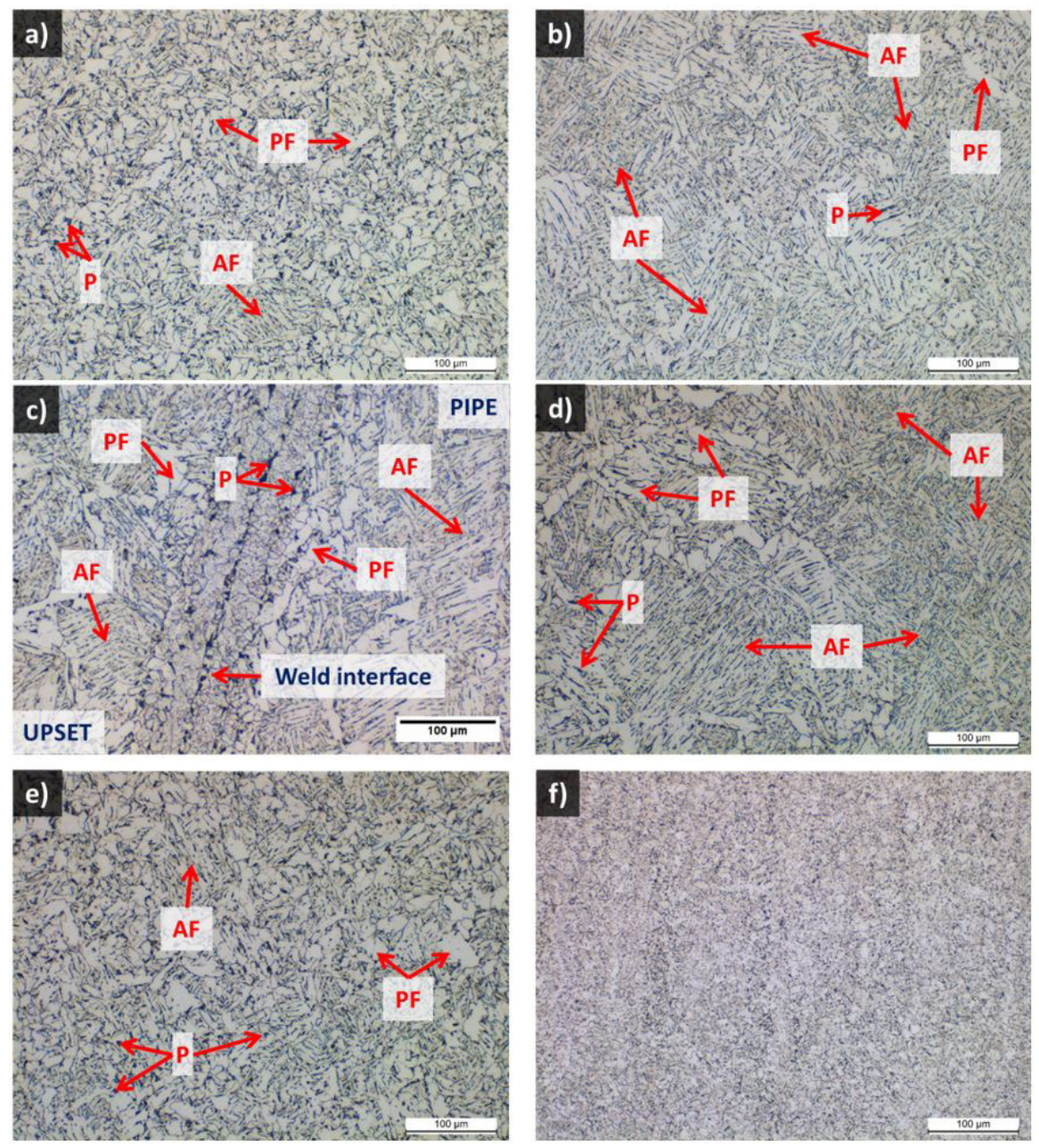

Figure 8. Microstructural analysis in different regions of the welded joint with 200x magnification. (a) upset HAZ; (b) upset TMAZ; (c) weld interface; (d) pipe TMAZ; (e) pipe HAZ; and (f) BM. Etching by Nital 5\%. 
Lemos et al.

Table 2. Results of fatigue tests

\begin{tabular}{|c|c|c|c|c|c|c|c|}
\hline Sp & $\begin{array}{c}\text { Range } \sigma \\
(\mathrm{MPa})\end{array}$ & $\sigma \max (\mathrm{MPa})$ & $\sigma \min (\mathrm{MPa})$ & $\begin{array}{c}\sigma \text { average } \\
\text { (MPa) }\end{array}$ & Ratio & $\begin{array}{l}\text { Runout } \\
\text { (cycles) }\end{array}$ & Comments \\
\hline 1 & 220 & 250 & 30 & 140 & 0.12 & $10^{6}$ & No fracture \\
\hline 2 & & 250 & 30 & 140 & 0.12 & $10^{6}$ & No fracture \\
\hline 3 & & 250 & 30 & 140 & 0.12 & $10^{6}$ & No fracture \\
\hline 4 & 200 & 220 & 20 & 120 & 0.091 & $10^{6}$ & No fracture \\
\hline 5 & & 220 & 20 & 120 & 0.091 & $10^{6}$ & No fracture \\
\hline 6 & & 220 & 20 & 120 & 0.091 & $10^{6}$ & No fracture \\
\hline 7 & 180 & 200 & 20 & 110 & 0.1 & $3 \times 10^{6}$ & No fracture \\
\hline 8 & & 200 & 20 & 110 & 0.1 & $3 \times 10^{6}$ & No fracture \\
\hline 9 & & 200 & 20 & 110 & 0.1 & $3 \times 10^{6}$ & No fracture \\
\hline
\end{tabular}

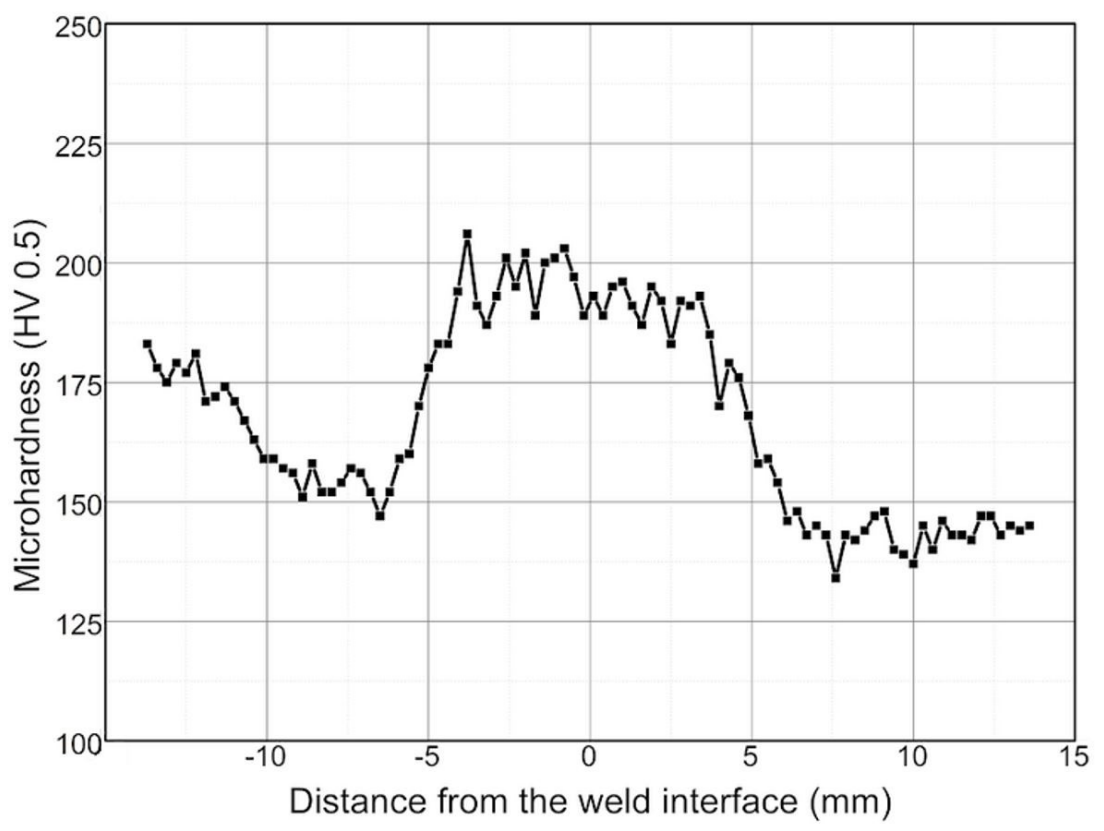

Figure 9. Cross section microhardness profile in the center of the welded joint.

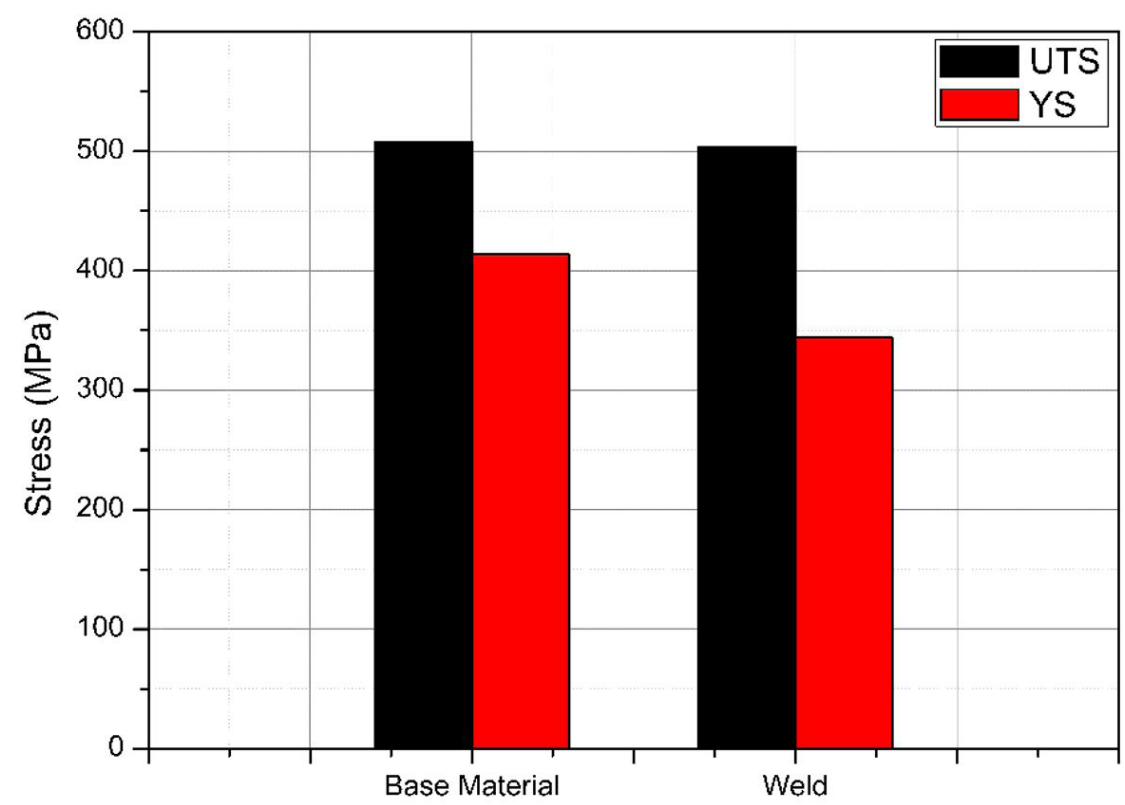

Figure 10. Average mechanical properties of BM pipe and welded joint by subsize specimens. 


\section{Conclusions}

The main objective of this work was to manufacture an upset end by friction welding in rigid pipes. The findings of this development can be summarized as follows:

i) The carbon steel pipe (base material) is shown as an API 5L X65 PSL2, according to the tensile tests and chemical composition;

ii) Welding geometry (tube to tube) was found to be promising. Regarding the macrostructure, a good surface appearance was reached and defects were not seen. Moreover, it was noted an increased microhardness in the weld zone that may be related to regions with aggregates of carbides and harder microstructures. As an average, the yield strength and ultimate tensile strength values of the joint were $344 \mathrm{MPa}$ and 504 $\mathrm{MPa}$, respectively. Finally, fatigue tests showed no fracture, which indicates high fatigue life.

\section{Acknowledgements}

The authors would like to show their gratitude to Prof. Dr Telmo Roberto Strohaecker (LAMEF-PPGE3MUFRGS) whose presence and wisdom will always be missed. In addition, we would like to acknowledge the financial support of Petrobras.

\section{References}

1 Sen TK. Probability of fatigue failure in steel catenary risers in deep water. Journal of Engineering Mechanics. 2006;132(9):1001-1006

2 Lemos GVB, Farina AB, Nunes RM, Cunha PHCP, Bergmann L, Santos JF, et al. Residual stress characterization in friction stir welds of alloy 625. Journal of Materials Research and Technology. 2019;8(3):2528-2537.

3 American Petroleum Institute. API specification 5L. 45th ed. Washington: API Publishing Services; 2012.

4 Aggarwal R, Mourelle MM, Kristoffersen S, Godinot H, Vargas P, Else M, et al. Development and qualification of alternate solutions for improved fatigue performance of deepwater steel catenary risers. In: American Society of Mechanical Engineers. Proceeding of the 26th International Conference on Offshore Mechanics and Arctic Engineering; 2007 June 10-15; San Diego, USA. Vol. 1: Offshore Technology; Special Symposium on Ocean Measurements and Their Influence on Design. USA: ASME; 2007. p. 315-329.

5 Aggarwal R, Bhat SU, Meling TS, Linden C, Mourelle MM, Else M. Qualification of enhanced SCR design solutions for improving fatigue life at touch down zone. In: International Society of Offshore and Polar Engineers. Proceedings of the 16th International Offshore and Polar Engineering Conference; 200628 May-2 June; San Francisco, USA. USA: ISOPE; 2006.

6 Mekha B, Hawkey B, Chandler BD, Fazackerley B, Stevens DM. State-of-the-Art SCR Qualification Program for 24 inch $\times 40 \mathrm{~mm}$ Thick Clad Pipe with Upset Ends for the Browse Project. In: Offshore Technology Conference; 2014 May 5-8; Texas, USA. USA: ISOPE; 2014.

7 Izquierdo A, Aggarwal R, Quintanilla H, García E, López V, Richard G, et al. Qualification of weldable X65 grade riser sections with upset ends to improve fatigue performance of deepwater steel catenary risers. In: International Society of Offshore and Polar Engineers. Proceedings of the 18th International Offshore and Polar Engineering Conference; 2008 July 6-11; Vancouver, Canada. USA: ISOPE; 2008. p. 71-79.

8 New Touch Down Zone (TDZ) Solutions for Steel Catenary Risers (SCRs). Development and qualification of alternative design solutions Joint Industry Project (JIP) report. USA: US Department of Interior, Minerals Management Service \& US Department of Transportation, Pipeline and Hazardous Materials Safety Administration; 2008.

9 Yue B, Campbell M, Walters D, Thompson H, Raghavan K. Improved SCR design for dynamic vessel applications. In: American Society of Mechanical Engineers Digital Collection. Proceeding of the 29th International Conference on Ocean, Offshore and Arctic Engineering; 2010 June 6-11; Shanghai, China. New York: ASME; 2010. p. 495-504.

10 Meyer A, Pauly D, Dos Santos JF, Pinheiro G, Roos A, Gibson D, et al. Considerations on robotic friction stitch welding for the repair of marine structures. In: Proceedings of 20th International Conference on Offshore Mechanics and Arctic Engineering; 2001 June 3-8; Rio de Janeiro, Brazil. Rio de Janeiro; p 145-151.

11 Santos GM, Formoso CM, Franco SD, Franco VLD S. Optimization of control parameters in a friction hydro pillar processing unit to repair oil steel structures. In ABCM Symp. Ser. Mechatron; 2012; Rio de Janeiro. Rio de Janeiro: ABCM; 2012. p. 73-82. 
12 Yeh FWT, Pereira da Cunha PHC, Lessa CRL, Clarke T, Strohaecker T. Evaluation of discontinuities in A36 steel repairs with friction hydro pillar processing using different axial forces. ISIJ International. 2013;53(12):2269-2271.

13 Lessa CR L. Soldagem FHPP: processo e metalurgia nas transformações das fases de um aço C-Mn [thesis]. Porto Alegre: Universidade Federal do Rio Grande do Sul; 2011.

14 Defalco J, Steel R. Friction stir process now welds steel pipe. Welding Journal. 2009;88(5):44-48.

15 ASM International. Welding, Brazing and soldering. Vol. 6. Materials Park: ASM; 1999.

16 Mishra RS, Ma ZY. Friction stir welding and processing. Materials Science and Engineering R Reports. 2005;50(12):1-78.

17 Crossland B. Friction welding: recommended practices for friction welding. Contemporary Physics. 1971;12(6):559574.

18 Blakemore GR. Friction welding: technology for the new millennium. In: Proceedings of the Offshore Technology Conference; 1999 May 3-6; Houston, USA. OTC; 1999.

19 ASM International. ASTM E8M: standard test methods for tension testing of metallic materials. Materials Park: ASM; 2016.

20 Anelli E, Colleluori D, Cumino G, Izquierdo A, Quintanilla H. Development of high grade seamless pipes for deepwater application by metallurgical design. In: Metallurgical Process Technology: Proceedings of the 2nd International Conference on New Developments; 2005 September 19-21; Riva del Garda. AIM; 2005.

21 Faes K, Dhooge A, Baets P, Afschrift P. Influence of deceleration phase on properties of friction welded pipelines using intermediate ring. Science and Technology of Welding and Joining. 2008;13(2):136-145.

22 Chludzinski M, Santos RE, Pissanti DR, Kroeff FC, Mattei F, Dalpiaz G, et al. Full-scale friction welding system for pipeline steels. Journal of Materials Research and Technology. 2019;8(2):1773-1780.

Received: 14 Aug. 2020

Accepted: 11 Nov. 2020 